\title{
NEST PREDATION IN THE AFRICAN BLUE TIT, CYANISTES TENERIFFAE (AVES, PARIDAE), USING NEST-BOXES AND ARTIFICIAL NESTS
}

\author{
R. Boulahbal ${ }^{1 \star}$, S. Benyacoub ${ }^{2}$, R. Rouag ${ }^{1}$ \\ ${ }^{1}$ Chadli Bendjedid University. B.P. 36000. El Tarf. Algeria \\ ${ }^{2}$ Badji Mokhtar University. Annaba. B.P. 23000. Algeria \\ E-mail:arrakisdz@yahoo.fr \\ ${ }^{*}$ Corresponding author \\ R. Boulahbal (https://orcid.org/ 0000-0001-8171-1354)
}

\begin{abstract}
Nest Predation in the African Blue Tit, Cyanistes teneriffae (Aves, Paridae), Using Nest-Boxes and Artificial Nests. Boulahbal, R., Slim Benyacoub, S., Rouag, R. - Predation on breeding blue tit populations in north-eastern Algeria has been studied in nest boxes during a five years fieldwork (20032007) in cork oak forests. Nest boxes were placed each year in Brabtia plain forest in El Kala National Park. Results have shown that mean nest predation rate is $51.74 \%$. Six patterns of nest predation have been described and five predators are probably involved: Common Genet, Great Spotted Woodpecker, Ocellated Lizard, Ants and Rodents. Genet is the major predator on tit nests. Mean predation rates on egg and nestling stages are similar. Artificial nests and natural nests had similar predation rates. Major predators on artificial nests were lizards and Rodents.
\end{abstract}

Key words: Algeria, forest habitats, blue tit, predation, life history traits.

\section{Introduction}

Studies on nest predation are an important part of avian research, including animal behaviour, population ecology, evolution and conservation biology (Ibanez-Alamo, 2015). Since decades, Blue Tit is considered as an interesting biological model in studies on cavity-nesting birds and their life history in the western Palearctic (Fargallo, 2004; Kvist et al., 2004). Those studies allowed better understanding of ecological processes influencing tit populations (Lambrechts al., 2004). Several studies in North Africa (Moali \& Isenmann, 1990; Chabi et al., 1995; Ziane, 2006) revealed a smaller clutch size, earlier laying dates and weaker reproductive success. This is due to a shorter reproductive period in the southern Mediterranean and poor-quality habitats compared to mid-European habitats (Blondel et al., 1993). Nest predation remained a non-explored aspect in blue tit bio-ecology in the south fringe of the mediterrranean. In this paper, we explore different aspects of nest predation in a blue tit population nesting in oak forests in northern Algeria. Being the major cause of nest failure in birds, predation is recognized as an important selective pressure in reproductive strategies and life history evolution (Martin 1993; Gustafsson 2005). However, data about nest predation remain scarce in several parts of the distribution range of the blue tit or have concerned relative species. In this study, we present the first data about nest predation in the African Blue Tit Cyanistes teneriffae Lesson, 1831.

\footnotetext{
Methods

Study area

This study was conducted over five years (2003-2007) in north eastern Algeria, in Brabtia district inside El Kala National Park (fig. 1). North-eastern is one of the rainiest areas of Algeria, having around $900 \mathrm{~mm}$ of annual rain. It has the largest south-mediterranean low-altitude forests, mainly cork oak and holm oak forests, and dense thermophile scrubs. Study habitat is a cork oak forest with $30 \%$ tree density and $7 \mathrm{~m}$ height. This forest has been lately burnt in 2000 . The understory is $50-80 \%$ density and $1.20 \mathrm{~m}$ height, where dominant species are Erica arborea, Calycotome villosa, Phillyrea media and Pistachia lentiscus, which are typical species of Mediterranean plain scrub.
} 
Reproductive parameters

We used wooden nest-boxes with $26 \mathrm{~mm}$ flying-hole diameter and $20 \mathrm{~cm}$ depth, placed by early March at $3 \mathrm{~m}$ height on oak trunks and at nearly $50 \mathrm{~m}$ distance from each other. Number of boxes was 30 in 2003 to 114 in 2006 and density was 6/10ha. Boxes were visited once a week. We checked nest building stages until egg laying, hatching and chicks fledging. Reproductive parameters were calculated for each nest, including laying date (date of first egg laid), clutch size (number of eggs laid), hatching success (proportion of hatched eggs), flying success (proportion of fledged nestlings) and reproductive success (number of fledged nestlings/number of eggs laid). Survival probability was calculated by Mayfield Method (Mayfield, 1975).

\section{Nest predation}

A nest was considered as attacked when following indices were observed: missing eggs or chicks, eggs destroyed inside nests, chicks injured and/or dead inside nest, disturbance of the nest structure. Combination of indices allowed us to describe patterns of nest predation. Predator's identification was based on literature (Martin \& Joron, 2003; Major, 1999, Christman \& Dhondt, 1997). Other observations helped us to assess predator's identities. We calculated nest predation rates during egg stage (rate of nests attacked during laying-incubation period), during nestling stage (rate of nests attacked during hatching-raising chicks period), and global predation rate during a season (rate of all nests attacked in both stages) or over five years. Mean predation rate was calculated over five years.

\section{Artificial nests}

We used artificial nests, built with Erica arborea twigs, baited with wax eggs of the same size than natural eggs. Artificial nests were placed inside unoccupied nest-boxes. Eggs removal or traces left on wax eggs were considered as an evidence of predation. We described nest predation patterns on artificial nets and predation rates were calculated. Comparison with natural nests was made only with egg stage due to absence of a nestling stage in artificial nests. Statistics were performed with R 2.14. Confidence intervals calculated at 0.05.

\section{Results}

\section{Reproductive parameters}

Mean annual occupation rate in nest-boxes is $53.54 \%$ (IC $=50.31-56.76)$ with no differences between years $\left(\chi^{2}=6.33, \mathrm{df}=4, \mathrm{p}=0.17\right)$. Mean annual laying date is April 14th (IC $=12-16 ; \mathrm{n}=5 \mathrm{y}$ ) with extreme laying dates on March 25th and May18th. Tits laid 4 to 12 eggs. Mean clutch size is 6.61 (IC $=6.41-6.80 ; n=5$ y). Mean hatching success is 0.68 ( $\mathrm{IC}=0.62-0.74, \mathrm{n}=5 \mathrm{y})$. Mean fledging success is $0.735(\mathrm{IC}=0.666-0.803 ; \mathrm{n}=5 \mathrm{y})$. Mean reproductive success is $0.511(\mathrm{IC}=0.448-0.573, \mathrm{n}=5 \mathrm{y})$.
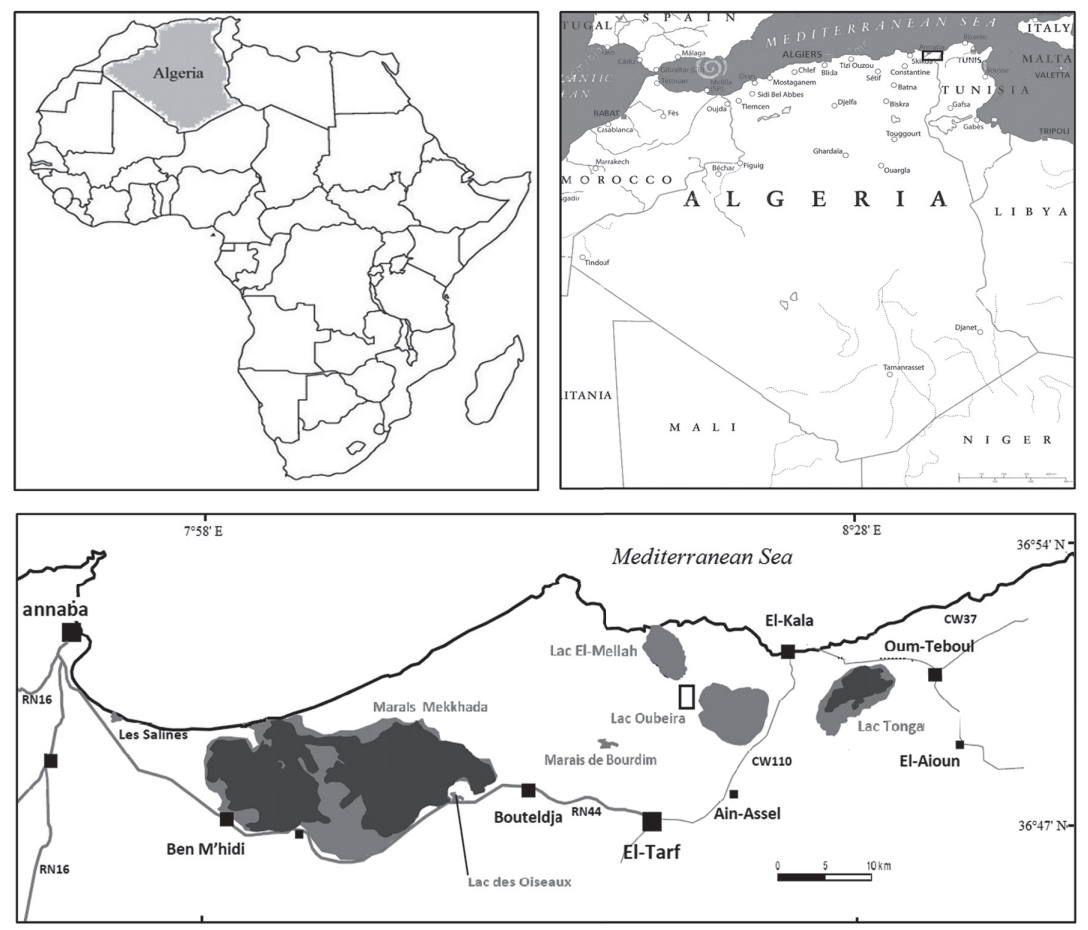

Fig. 1. Location of the study area. 


\section{Predation on natural nests}

Over five years, 173 predations were recorded. Mean predation rate was 51.74 (CI95 \% = $49.666,53.814 ; \mathrm{n}=5 \mathrm{y}$ ) varying from $36.36 \%$ ( $\mathrm{n}=11$ nests) in 2003 to $74.19 \%$ ( $\mathrm{n}=31$ nests) in 2007. Increasing predation rate observed was not significant $\left(\mathrm{khi}^{2}=9.12 ; \mathrm{p}=0.058 ; \mathrm{df}=4\right)($ fig. 2$)$. Patterns of nest predation

Six predation patterns have been observed and described as shown in table 1. Pattern A was observed only during egg stage. It concerned $21.38 \%$ of all predations. In this pattern, eggs disappear from the nest and nest-structure remains intact. In Pattern $\mathbf{B}$, also observed in egg stage, eggs are found destroyed and consumed inside nest-box. Nest structure is slightly disturbed. This pattern was observed in $4.04 \%$ of predations. Pattern $\mathbf{C}$ was the most frequent with $35.26 \%$ of all predations. Nests are totally destroyed and returned upside down inside nest-boxes. In this pattern, observed on both egg and nestling stages, eggs are usually found lying on bottom of the nest-box, mostly intact or sometimes destroyed. During nestling stage, chicks are mostly absent. Sometimes one or two chicks are found dead (intact and/or injured). Sometimes also, adult feathers are found, indicating adult predation. Egg and nestling stages were equally attacked $\left(\chi^{2}=0.71, \mathrm{df}=1, \mathrm{p}=0.398\right)$ in this pattern. Pattern D was observed mostly during nestling stage. This model was observed in $18.49 \%$ of predations. Nestlings are absent and some of nest material is taken off, outside flying hole of the nest-box. In Pattern E, eggs are found nibbled and consumed from inside. Empty eggshells are left. This model was observed in $9.82 \%$ of predations. Finally, $11 \%$ of observed predations, named pattern $\mathbf{F}$ correspond to what we assume being an indirect predation, i. e. abandonment of nest for supposed parents predations outside nests, leading to brood loss.

\section{Egg versus nestling stage}

Mean predation rates in egg and nestling stages over five years were respectively $32.61 \%$ CI $[29.8304,34.9896]$ and $28.60 \%$ CI $[27.157,30.043]$. No difference is recorded (X-squared = $0.16785, \mathrm{df}=1$, p-value $=0.682$ ). Survival probabilities, calculated by Mayfield method, during egg stage and nestling stage were similar $(0.225$ vs 0.200$)$. During egg stage, most frequent patterns observed were C, A and E. During nestling stage, patterns $C$ and D were the most frequent.

\section{Predation on artificial nests}

Mean predation rate on artificial nest was $39.3 \%$ ( $\mathrm{IC}=33.00-45.59 ; \mathrm{n}=5$ years). Mean predation rate on artificial nests and natural nests were similar, $39.3 \%$ vs $42.38 \%$; $(\mathrm{t}=0.70$, $\mathrm{df}=4 ; \mathrm{p}=0.49)$. Comparison is made only with egg stage in natural nests. We noted the same predation patterns on artificial nests. Predation pattern were the same on both nest types but had different frequencies. Model $\mathrm{C}$ is the most frequent pattern on natural nests but the less frequent on artificial nests (35.26\% in natural nests $v s 4.65 \%$ of predations in artificial nests, $\left.\chi^{2}=30.81, \mathrm{df}=1, \mathrm{p}<0.001\right)$ indicating that this predator makes a clear distinction between both types of nests. Moreover, frequencies of patterns $\mathrm{A}$ and $\mathrm{B}$ increased very significantly on artificial nests $\left(21.38 \%\right.$ to $\left.62.79 \% ; \chi^{2}=45.3 ; \mathrm{df}=1, \mathrm{p}<0.001\right)$ and $4.04 \%$ to $13.95 \%\left(\chi^{2}=19.99, \mathrm{df}=1, \mathrm{p}<0.001\right)$ for pattern $\mathrm{B}$.

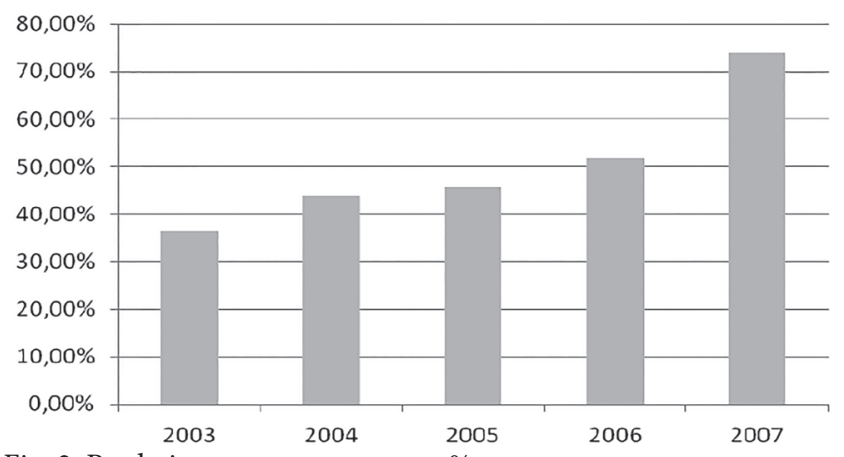

Fig. 2. Predation rates versus years, $\%$. 
Table 1. Patterns of nest predation

\begin{tabular}{cl}
\hline Pattern & \multicolumn{1}{c}{ Description } \\
\hline A & Egg disappearance. Nest structure intact. \\
B & Eggs destroyed and consumed inside nest. Nest structure slightly disturbed. \\
C & Nest totally returned and destroyed inside nest-box. Eggs found lying on bottom. \\
& Chicks absent and/or found dead injured. \\
D & Chick's disappearance. Some nest material found taken off flying hole of nest-box. \\
E & Clearly ants on chicks or eggs. \\
F & Indirect predation due to supposed predation of at least of the parents outside nest which conse- \\
& quence is the loss of brood.
\end{tabular}

Natural nests versus artificial nests

Global predation rates on natural and artificial nests were similar $\left(\chi^{2}=2.048, \mathrm{df}=\right.$ 1 , p-value $=0.152)$. Patterns $\mathrm{A}$ and $\mathrm{B}$ were more frequently observed on artificial nests, respectively $21.38 \%$ vs $62.79 \%\left(\chi^{2}=45.3 ; \mathrm{df}=1, \mathrm{p}<0.001\right)$ for pattern $\mathbf{A}$ and $4.04 \%$ to $13.95 \%\left(\chi^{2}=19.99, \mathrm{df}=1, \mathrm{p}<0.001\right)$ for pattern $\mathbf{B}$. Pattern $\mathbf{C}$ is the most frequently observed on natural nests but the less frequent on artificial nests (35.26\% in natural nests vs $4.65 \%$ of predations in artificial nests, $\left.\chi^{2}=30.81, \mathrm{df}=1, \mathrm{p}<0.001\right)$. Pattern $\mathbf{E}$ was observed in similar frequencies on both nest types $\left(\chi^{2}=2.5 ; \mathrm{df}=1 ; \mathrm{p}=0.11\right)$. Pattern $\mathrm{F}$ is absent on artificial nests.

\section{Discussion}

During study period, we described patterns of nest predation observed. Several studies were helpful in interpreting indices observed during field work (Martin \& Joron, 2003; Major, 1999; Christman \& Dhondt, 1997). Artificial nests were helpful in that matter, like reported in Burke et al. (2004); Major \& Kendhal (1996) and Pärt \& Wrentenberg (2002). Here, we propose a list of nest predators of African Blue Tit population nesting in cork oak forests. Those predators belong to different animal taxa: Mammals, Birds, Reptiles and Ants (fig. 3).

Pattern $\mathbf{A}$ is attributed to Reptiles, most probably Timon pater which was often observed climbing tree trunks. This lizard had been captured twice inside nest-boxes baited with artificial nests. Reptiles take eggs and don't leave traces after nest visiting (Christman \& Dhondt, 1997; Pärt \& Wrentenberg, 2002). Other Reptiles like snakes can also attack nests (Weatherhead \& Blouin-Demers, 2004). In our study area, during five years, no significant observations let us think that snakes could be possible predators. Finally, we think that big Tarentola individuals could steal eggs. In artificial nests, homodont teeth traces on wax eggs, typical of lizards, have been frequently observed.

Pattern B is attributed to Rodents. Rodents are nocturnal predators. They consume eggs and leave eggshells. Nest structure is slightly disturbed (Christman \& Dhondt, 1997). Most probable rodent predator is Apodemus sylvaticus, known to be a good tree climber (Walankiewicz, 2002). This rodent is abundant in the study area. Pattern C belongs certainly to Genetta genetta, as reported in Moreno-Rueda (2005) and Diaz \& Carrascal (2006). Several local observers already reported Genet attacks on nest-boxes in field works of precedent studies. We suppose that Genet introduces its anterior leg in the flying hole to catch preys inside nest-box. When moving around its arm, nest structure is destroyed. Nestlings or adults could be easily caught but not eggs. Hand conformation of genet does not give it the ability to hold eggs. This is the reason why those are mostly found lying on bottom of nest-box.

Pattern $\mathbf{D}$ is attributed to birds, most probably Great Spotted wood-peaker Dendrocopos major. This bird is well known to attack directly nest-boxes, often enlarging flying-holes (Nilsson, 1984; Moreno-Rueda, 2005). In 2005, flying holes of $25 \%$ of nest-boxes had been enlarged, even non-occupied boxes. Great Spotted wood-peaker is one of the major predators on tits and pied-flycatchers nesting in natural cavities (Walankiewicz, 2002). 
Pattern E is due to ants Crematogaster scutellaris and Camponotus cruentatus. The former species is very abundant in cork oak trees and have several interactions with tits. Ants usually invade nests after nestling fledging, cleaning up the nest from all organic fragments. They also can be predators of eggs and nestlings (Lambrechts et al., 2008). We sometimes observed ants biting and injuring nestlings of 2-3 days. Beside, dead nestlings are frequently eaten by ants. This is not considered as a predation. In artificial nests, wax eggs are often attacked and nibbled by ants. Wax fragments are not consumed though. They are found on nest borders.

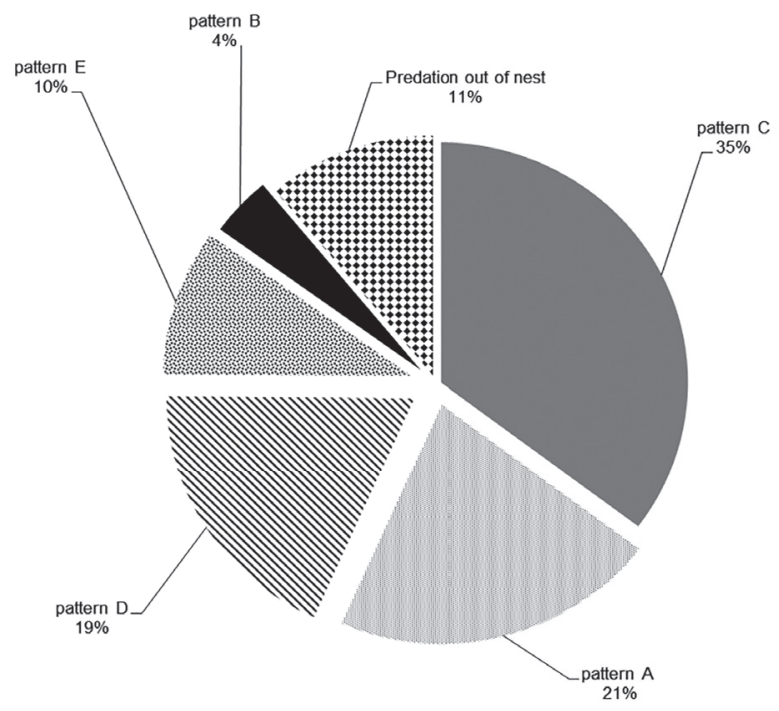

Fig. 3. Predation typology in nest-boxes, \%.

\section{Effects of nest predation on tit population}

In all years, predation was the main source of mortality in the studied tit population. We first hypothesized that nestlings were under stronger predation than eggs due to important activity in the nest when parents raise chicks. Factors such as odours, sounds, movements of parents around nests make nests more attractive to predators, as reported in some works, but predation rates on both stages were similar. Lau et al. (1998) on their side reported stronger predation on eggs. Opposite results show that different patterns exist throughout biogeographically different regions and different predators communities. One essential point is to know the major predators on a prey population and their ethology (Weidinger, 2002; Lahti, 2009). Major predators can have important effects of life history traits of bird populations.

Results from artificial nests allowed us to get useful information about predator's identity and action (Burke et al., 2004; Major \& Kendhal, 1996; Pärt \& Wrentenberg, 2002). For example, we could attest the importance of odour attractiveness to nests in the genet. This night predator almost systematically avoided artificial nests though these were located among natural ones. On another hand, the significant increase of other predator's action like Reptiles and Rodents on artificial nests is most probably due to absence of parental defence on these nests (Creswell, 1997) making evidence of the importance of parental nest defence in preventing nest predation. Both types of nests were equally predated, by the same predators. Grégoire et al. (2003) reported the same results; other works showed differences between natural and artificial nest (Pärt \& Wretenberg, 2002). Results from artificial nests should be though considered more as an information complement or an approximation on predation on natural nests (Major \& Kendhal, 1996). In our study, differences were in the importance of predators' pressure on each type of nests, indicating that those are influenced by different attractiveness factors, such as odour, sight, parental activity and nestling begging (Martin et al., 2000).

This study was supported by the Algerian Ministry of Higher Education and Scientific Research and the national park of El Kala. Acknowledgements to Annaba University and El Tarf University for supporting this work. 


\section{References}

Blondel, J., Dias, P.C., Maistre, M., Perret, P. 1993. Habitat heterogeneity and life-history variation of Meditrranean Blue Tit (Parus caeruleus). The Auk, 110 (3), 511-520

Burke, D., Elliott, K., Moore, L., Dunford, W., Nol, E. 2004. Patterns on nest predation on artificial and natural nests in forests. Conservation biology, 18 (2), 381-388.

Chabi Y., Isenmann P., Benyacoub S., Samraoui B. 1995. Breeding biology of the north-african blue tit (Parus caeruleus ultramarinus) in two semi-evergreen oak forests in Algeria. Terre et vie, 50, 133-140.

Christman, B. J., Dhondt, A. A. 1997. Nest predation in black-capped chickadees: how safe are cavity nests? The Auk 114 (4), 769-773.

Creswell, W. 1997. Nest predation: the relative effect of nest characteristics, clutch size and parental behaviour. Animal Behaviour, 53, 93-103.

Diaz, L., Carrascal, L. M. 2006. Influence of habitat structure and nest site features on predation pressure of artificial nests in mediterranean oaks forests. Ardeola, 53 (1), 69 - 81.

Fargallo, J. A. 2004. Latitudinal trends of reproductive traits in the blue tit Parus caeruleus. Ardeola, 51 (1),177-190.

Gregoire, A., Garnier, S., Dreano, N., Faivre, B. 2003. Nest predation in blackbirds (Turdus merula) and the influence of nest characteristics. Ornis Fennica, 80, 1-10.

Gustafsson, T. 2005. Nest predation in birds. Important concepts and methodological problems. Uppsala, 22, $2-17$.

Ibáñez-Álamo, J. D., Magrath, R. D., Oteyza, J. C., Chalfoun, A. D., Haff, T. M., Schmidt, K. A., Thomson, R. L., Martin, T. E. 2015. Nest predation research: recent findings and future perspectives. Journal of Ornithology, 156, 247-262

Kvist, L., Viiri, K., Dias, P.C., Rytkönen, S., Orell, M. 2004. Glacial history and colonization of Europe by the blue tits Parus caruleus. Journal of Avian Biology, 35, 352-359.

Lahti, D. C. 2009. Why we have been able to generalize about nest predation. Animal Conservation, 12, $279-281$.

Lambrechts, M. M., Caro, S., Charmantier, A., Gross, N., Galan, M. J., Perret, P., Cartan-Son, M., Dias, P. C., Blondel, J., Thomas, D. W. 2004. Habitat quality as a predictor of spatial variation in blue tit reproductive performance: a multi-plot analysis in a heterogeneous landscape. Oecologia, 141, 555-561.

Lambrechts, M. M., Schatz, B., Bourgault, P. 2008. Interactions between ants and breeding Paridae in two distinct Corsican oak habitats. Folia Zool., 57 (3), 264-268.

Lau, P., Bosque, C. \& Strul, S. D. 1998. Nest predation in relation to nest placement in the greater ant Crotophaga major. Ornithologia neotropical, 9, 87-92.

Major, R. E., Kendhal C.,E. 1996. The contribution of artificial nest experiment to understanding avian reproductive success: a review of methods and conclusions. Ibis, 138, 298-307.

Major, R. E. 1999. The effect of human observers on the intensity of nest predation. Ibis, 132, 608-612.

Martin, J. L., Joron, M. 2003. Nest predation in forest birds: influence of predator type and predator's habitat quality. Oikos, 102, 641-653.

Martin, T. E., Scott, J., Menge, C. 2000. Nest predation increases with parental activity: separating nest site and parental activity effects. Proc.Roy.Soc.Lond., 267, 2287-2293.

Martin, T. E. 1993. Nest predation and nest sites. New perspectives and old patterns. Bioscience, 43 (8), 523-532.

Mayfield, H. F. 1975. Suggestions for calculating nest success. wilson bulletin of ornithology, 87 (4), 456-466.

Moali, A., Isenmann P. 1990. The timing of breeding and clutch size of blue tits (Parus caeruleus) in two montane habitats in Algeria. In: Blondel, J., Gosler, A., Lebreton, J. D., McCleery, R., eds. Population Biology of Passerine Birds. NATO ASI Series (Series G: Ecological Sciences), vol 24. Springer, Berlin, Heidelberg.

Moreno-Rueda, G. 2005. A trade-off between predation risk and sibling competition in the begging behaviour of coal and great tits. J. Field Ornithology, 76 (4), 390-394.

Nilsson, S. G. 1984. The evolution of nest site selection among whole nesting birds: the importance of nest predation and competition. Ornis Scandinavica, 15, 167-175.

Pärt, T., Wretenberg, J. 2002. Does artificial nests reveal nest predation risk for real nests? Journal of Avian Biology, 33, 39-46.

Walankiewicz, W. 2002. Nest predation as a limiting factor to the breeding population size of the collared flycatcher Ficedula albicollis in the Bialowieza National Park (NE Poland). Acta Ornithologica, 37 (2), 91-106.

Weatherhead, P. J., Blouin-Demers, G. 2004. Understanding avian nest predation : why ornithologists should study snakes? Journal of avian biology, 35, 185-190.

Weidinger, K. 2002. Interactive effects of concealment, parental behaviour and predators on the survival of open passerine nests. J. Animal Ecology, 71, 424-437.

Ziane, N., Chabi, Y., Lambrechts, M. M. 2006. Breeding performances of blue tit Cyanistes caeruleus ultramarinus in relation to habitat richness of oak forest patches in north-eastern Algeria. Acta Ornithologica, 41, 163-169. 